\title{
Indirect Method versus Direct Method for Measuring Ventilation Rates in Naturally Ventilated Dairy Houses
}

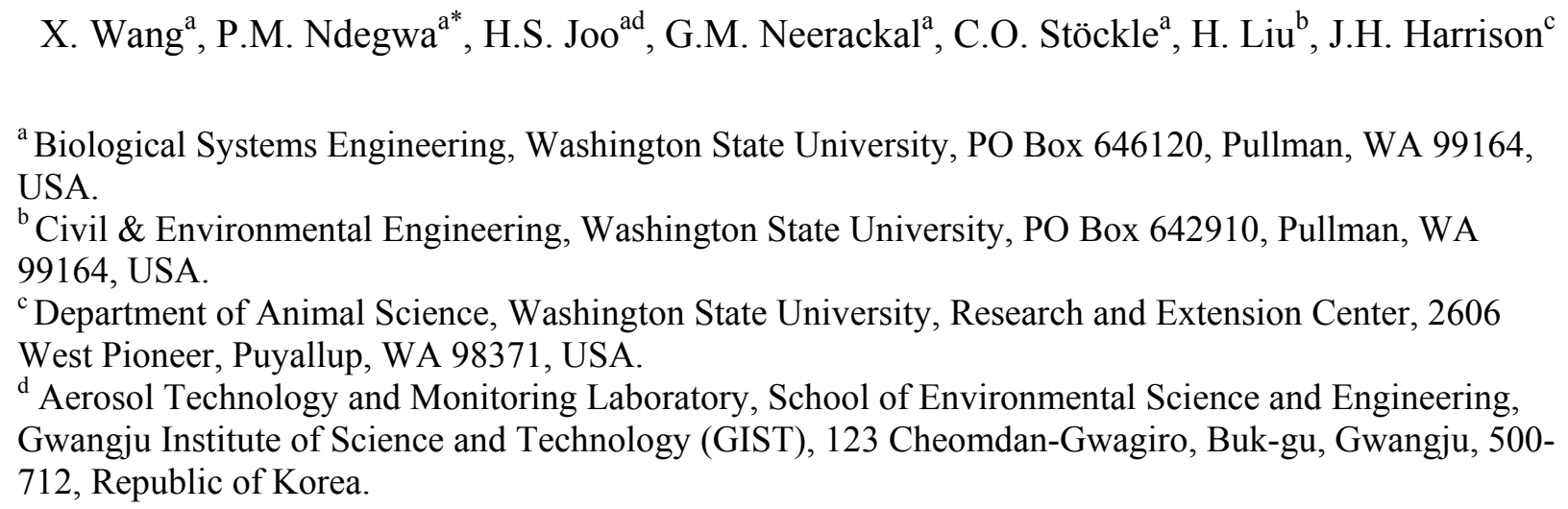

"Corresponding author: Phone: 509-335-8167; Fax: 509-335-2722; Email: ndegwa@wsu.edu.

\section{ABSTRACT}

Indirect methods are widely used for determining air exchange rates (AER) in naturally ventilated barns because they are relatively easier and cheaper than direct methods, which measure actual airflow in and out of the barns. The main goal of this study was to evaluate a common indirect method $\left(\mathrm{CO}_{2}\right.$ mass balance) against a direct method, and identify factors influencing this indirect method. The mean AER based on 24-h averaging, irrespective of method, ranged from 13 to $39 \mathrm{~h}^{-1}$ during the study-periods. The $\mathrm{CO}_{2}$-balance method tended to overestimate barn AER. The cows' $\mathrm{CO}_{2}$ production rate, in the current study, was estimated at

$0.178 \mathrm{~m}^{3} \mathrm{~h}^{-1} \mathrm{hpu}^{-1}$ based on 24 - $\mathrm{h}$ averaging. The $\mathrm{CO}_{2}$-balance method with $24-\mathrm{h}$ data averaging yielded more reliable barn AER than with shorter averaging times (i.e., 1, 2, and $12 \mathrm{~h}$ ). The 1-h averaging, however, was chosen to analyze the effects of other pertinent factors on the $\mathrm{CO}_{2}$ balance method to capture diurnal variations of AER. Both wind speed and wind direction had significant effects on barn AER as well as the difference between the $\mathrm{CO}_{2}$-balance method and direct method. Barn AER, in general, increased with wind speed. The $\mathrm{CO}_{2}$-balance method was unreliable during milking times, and when indoor-outdoor $\mathrm{CO}_{2}$ concentration and temperature differences were less than $70 \mathrm{ppm}$ and $0^{\circ} \mathrm{C}$, respectively.

\section{KEYWORDS:}

Natural ventilation; carbon dioxide balance; air exchange rate; direct method; emission 


\section{Nomenclature}

35 A opening area $\left(\mathrm{m}^{2}\right)$

$36 A_{\mathrm{CO}_{2}}^{\prime}$ relative animal activity

$37 \bar{A}_{\text {daily }}$ daily mean animal activity

$38 \bar{A}_{\text {hourly }}$ hourly mean animal activities

$39 \mathrm{AER}_{\mathrm{CO}_{2}}$ air exchange rate by $\mathrm{CO}_{2}$-balance method $\left(\mathrm{h}^{-1}\right)$

$40 A E R_{\text {Direct }}$ air exchange rate by direct method $\left(\mathrm{h}^{-1}\right)$

$41 C_{\text {in }} \quad \mathrm{CO}_{2}$ concentration at the inlet (ppm)

$42 C_{\text {out }} \quad \mathrm{CO}_{2}$ concentration at the outlet (ppm)

$43 C_{\text {prod }} \mathrm{CO}_{2}$ production on a $24-\mathrm{h}$ basis $\left(\mathrm{m}^{3} \mathrm{~h}^{-1}\right)$

$44 \quad d_{p}$ days of pregnancy

$45 \quad H P U \quad 1000 \mathrm{~W}$ of the total heat produced by the animals at $20^{\circ} \mathrm{C}$

$46 m$ body mass of the cow $\left(\mathrm{kg} \mathrm{cow}^{-1}\right)$

$47 \quad Q \quad$ airflow through the opening $\left(\mathrm{m}^{3} \mathrm{~h}^{-1}\right)$

$48 T_{\text {ind }}$ indoor temperature $\left({ }^{\circ} \mathrm{C}\right)$

$49 \quad v \quad$ perpendicular air velocity to the opening $\left(\mathrm{m} \mathrm{s}^{-1}\right)$

$50 \quad V \quad$ barn volume $\left(\mathrm{m}^{3}\right)$

$51 \quad Y$ milk yield $\left(\mathrm{kg} \mathrm{cow}^{-1} \mathrm{~d}^{-1}\right)$

$52 \phi_{p}$ heat dissipation due to pregnancy (W)

$53 \phi_{L M}$ heat dissipation due to maintenance of essential function (W)

$54 \quad \phi_{M Y}$ heat dissipation due to milk yield (W)

$55 \phi_{\text {tot }}$ total heat production by the animals at $20^{\circ} \mathrm{C}(\mathrm{W})$

$56 \phi^{*}{ }_{\text {tot }}$ total heat production corrected for temperature other than $20^{\circ} \mathrm{C}(\mathrm{W})$ 


\section{Introduction}

Accurate and reliable measurements of gaseous emissions in animal husbandry are critical for development and evaluation of mitigation strategies and compilation of national emission inventories. Quantifying gaseous emissions from naturally ventilated barns, however, has additional challenges primarily because of the complexity of air exchange rates (AER) determination (Kiwan et al., 2012; Ogink et al., 2013). Natural ventilation (NV) systems in dairy

64 barns are commonly used in regions with mild climate due to low capital and low energy demand (Andonov et al., 2003; Joo et al., 2014; Joo et al., 2015b). However, AER in NV barns are directly dependent on atmospheric conditions (Snell et al., 2003; Ngwabie et al., 2011). Uncertainties due to changes in meteorological conditions, therefore, further complicate estimation of AER in NV buildings.

The fundamental approach of determining AER in a NV building is direct measurement of airflow at the inlets and outlets of the building (hence: direct method). To achieve this, wind velocities at the openings are then coupled with relevant openings' areas to determine total airflow either in or out of the building. The advantages of this direct approach, over indirect methods, include: (i) high frequency of simultaneous readings at numerous points, and (ii) less influences of measurements from animal physiology or behavior. Direct measurements of AER in the field, however, are few due to substantial initial investment required (Flourentzou et al., 1998; Kiwan et al., 2012; Joo et al., 2014). The accuracy of direct method mainly depends on the number of measurement points because wind velocity sensors can measure only local air velocities while wind velocities at different positions of the ventilation openings may vary significantly (Ozcan et al., 2007). Increasing the numbers of the sensors overcomes this drawback but also increases the cost. In previous studies (Joo et al., 2014), 16 ultrasonic anemometers (sonics) were installed at select points of the barn openings to measure air velocity at respective air inlets and outlets. This research concluded that the sum of airflows through all openings acting as inlets was the best measure of barn ventilation rate for that given period.

The AER for NV buildings are also measured using indirect methods such as tracer gas techniques (TGT), the $\mathrm{CO}_{2}$-mass balance, $\mathrm{H}_{2} \mathrm{O}$-mass balance, and sensible heat balance methods.

87 NV buildings ( 
tracer gases and has indicated larger inconsistences compared to the $\mathrm{CO}_{2}$-balance method, which

90 is another form of tracer gas application (Samer et al., 2014). The $\mathrm{CO}_{2}$-balance method, based on

$91 \mathrm{CO}_{2}$ production by animals, is one of the most commonly used methods in NV buildings (CIGR,

92 1984, 2002). Research indicated that the $\mathrm{CO}_{2}$-balance method agreed well with direct method in

93 mechanically ventilated barns (Blanes and Pedersen, 2005; Li et al., 2005; Xin et al., 2009).

94 Another commonly used indirect method is the $\mathrm{H}_{2} \mathrm{O}$ mass balances between air inside and

95 outside buildings, which is a function of water produced by animals via respiration and

96 evaporation from manure and forage (Pedersen et al., 1998; Chepete and Xin, 2004; Blanes and

97 Pedersen, 2005; Samer et al., 2012a; Samer et al., 2012b). The sensible heat balance method,

98 which is based on animal's heat production rate, is not recommended for uninsulated buildings

99 due to high potential errors when estimating heat transmission loss from such building (Pedersen

100 et al., 1998). The accuracy of these indirect methods, however, depends on $\mathrm{CO}_{2}, \mathrm{H}_{2} \mathrm{O}$, and heat

101 produced by the housed livestock, which vary with animal weight, productivity, manure

102 management system, and pregnancy conditions. Major sources of errors also include:

103 unaccounted $\mathrm{CO}_{2}$ and $\mathrm{H}_{2} \mathrm{O}$ produced from manure, variations in meteorological conditions,

104 locations of sampling points, and inadequacy of associated models (i.e. models not able to

105 account for diurnal variations). Although the effects of these factors on these indirect methods

106 are well recognized, their respective effects have not been adequately addressed in previous

107 research. Furthermore, performance of one indirect method has often invariably been evaluated

108 against another indirect method, which may also suffer from similar constraints.

109 The specific objectives of this study, therefore, were to: (i) evaluate the performances of the 110 most commonly used indirect method $\left(\mathrm{CO}_{2}\right.$-mass balance) against a direct method in $\mathrm{NV}$ dairy 111 barns, and (ii) investigate the effects of pertinent factors (season, integration time, milking time,

112 wind speed and direction, and differences in indoor-outdoor $\mathrm{CO}_{2}$ concentrations and

113 temperatures) on the $\mathrm{CO}_{2}$-balance method.

115 2. Materials and Methods

1162.1 Dairy Site and Building Description

117 These studies were conducted in a NV dairy barn on a commercial operation located in

118 Central Washington. The data presented in this paper were collected in four separate periods 
119 (March, May, July, and September), each of them consisting of seven consecutive measurement

120 campaign days. The dairy consisted of six symmetrically distributed freestall NV dairy buildings

121 and other dairy amenities including: milking parlor, feed storage and mixing, and manure

122 storages and treatment facilities (settling basins, drying ponds, composting area, etc.) (Fig.1).

123 The bedding material for the cows, in the freestalls, was mature manure compost. Wastewater

124 from the secondary lagoon was used to flush manure in the manure-alleys every $6 \mathrm{~h}$. Barn 2 ,

125 which had a capacity for 850 Holstein cows, was selected for studies reported in this paper. The

126 on farm instrument shelter (OFIS) was located between barns 1 and 2.

127 The study barn (B2) was $213 \mathrm{~m}$ long and $39 \mathrm{~m}$ wide and was partitioned into two equal pens

128 by a concrete pad feed alley (Fig. 2). The height of roof varied from $3.6 \mathrm{~m}$ at the sidewalls to

$12911.0 \mathrm{~m}$ at the gable peak. The barn had an open ridge ( $1.85 \mathrm{~m}$ wide) and space boards covering

130 the gables of the east and west end-walls. Each of the longer south and north sidewalls of B2 had

131 two side-by-side adjustable side curtains to allow control of natural ventilation. Usually one or

132 both curtains were closed from November to March because of the prevalent windy and cold

133 conditions. When both curtains were closed, there was still a 40-cm opening between the top

134 curtain and the eave.

\subsection{Instrument Setup and Data Acquisition}

137 Wind velocities, perpendicular to barn openings, were continuously measured with 16 three-

138 dimensional (3-D) sonics (Model 81000, R.M. Young Co., Traverse City, MI) as shown in Fig. 3.

139 Twelve sonics were distributed amongst the four sidewalls, while four units were mounted at the

140 open ridge of the barn. The barn was divided lengthwise into four equal virtual sections. The

141 sidewall sonics were mounted at approximately the midpoint of each section with the sensors

142 positioned in the middle of the opening between the eave and the top edge of upper curtain. The

143 four sonics in the ridge opening were mounted horizontally at the midpoint of each section. Each

144 endwall was divided evenly into two virtual sections. The two sonics in each endwall were

145 installed at the horizontal and vertical midpoints of each section.

146 Carbon dioxide concentrations were measured continuously using a photoacoustic IR multigas

147 monitor (Model 1412, Innova AirTech Instruments, Ballerup, Denmark). The Model 1412 was

148 equipped with an internal cross compensation algorithm for target gases as well as temperature 
and pressure fluctuations. Our unit was outfitted with a set of six filters for $\mathrm{NH}_{3}, \mathrm{~N}_{2} \mathrm{O}, \mathrm{CO}_{2}$,

$150 \mathrm{CH}_{3} \mathrm{OH}, \mathrm{CH}_{4}$, and $\mathrm{H}_{2} \mathrm{O}$ configured to ensure internal cross compensation among these gases.

151 Sixteen sampling ports were located adjacent to each sonic around the barn perimeter. Each

152 sampling port was provided with an air filter. The four sampling ports at each sidewall or on the

153 ridge were combined into one composite sample line, while the two sampling ports on each

154 endwall were pooled together to yield a composite sample line for each endwall. In effect, the

155 sampling lines summed up to ten: five for barn 1 and five for barn 2 (B1 was also monitored

156 during the study period but its data are not included in this paper). Samples from all sampling

157 lines, for concentration measurements, were drawn sequentially at intervals of $10 \mathrm{~min}$ and it thus

158 took $100 \mathrm{~min}$ to complete a sampling cycle. Collection, conveyance, and analyses of gas were

159 described in detailed in Joo et al. (2014) and Joo et al. (2015a).

160 Three activity sensors (Passive Infrared Detector, model SRN-2000N, Visonic Inc.,

161 Bloomfield, CT) were installed in barn 2 as shown in Fig. 3. Each of two sensors within the pens

162 monitored cow movement in the east and west halves of the barn. These two sensors were

163 located adjacent to trough and feed areas where they faced the maximum number of animals. The

164 third sensor, which was pointed to the central feed alley of the barn, was used to monitor vehicle

165 traffic. The maximum coverage of the activity sensor was $18 \mathrm{~m} \times 18 \mathrm{~m}$ which effectively

166 covered the entire width of each pen.

167 The ambient meteorological conditions were measured with a weather station installed in the 168 middle of B1 ridge. The weather station consisted of a solar radiation shielded relative humidity 169 (RH)-temperature probe (NOVUS Model RHT-WM, Novus Electronics, Porto Alegre, Brazil), a 170 solar radiation pyranometer (Model LI-200SL, LiCOR, Lincoln, NE) and a wind anemometer 171 (Model 03002VM Wind Sentry, R.M. Young Co., Traverse City, MI). The air temperature and 172 relative humidity inside the barn were recorded using a RH-temperature probe (NOVUS Model 173 RHT-WM, Novus Electronics, Porto Alegre, Brazil) located near the middle of the barn at a 174 height of approximately $8 \mathrm{~m}$. The sonics also provided additional temperature measurements 175 besides the air velocity measurements.

176 The measurement data were measured automatically each second and averaged and recorded 177 every minute using a DAC (data acquisition and control) hardware and an AirDAC (air 178 emissions data acquisition and control) software custom-developed by Purdue University and 
179 National Instrument to control the sampling duration, sequence, and frequency of gas sampling

180 lines (Ni and Heber, 2010; Joo et al., 2014; Joo et al., 2015a).

\subsection{Theories and Methods}

\section{$183 \quad 2.3 .1$ Direct method}

184 The direct method applies the fluid continuity equation (Eq. 1) to compute barn ventilation rates (Joo et al., 2014) and Eq. (2) to determine AER.

$$
Q=3600 v A
$$

$$
A E R_{\text {Direct }}=Q / V
$$

Where: $Q$ is airflow through an opening $\left(\mathrm{m}^{3} \mathrm{~h}^{-1}\right) ; v$ is the average perpendicular air velocity to the face of the opening $\left(\mathrm{m} \mathrm{s}^{-1}\right) ; A$ is the opening area $\left(\mathrm{m}^{2}\right)$, for a given barn inlet or outlet; $A E R_{\text {Direct }}$ is air exchange rate by direct method $\left(\mathrm{h}^{-1}\right)$; and $V$ is the barn volume $\left(\mathrm{m}^{3}\right)$.

191 Each of the five barn openings (four walls plus the ridge), at any given period, was either an

192 inlet or outlet depending on the prevailing wind directions. Total air inflow rates were used to 193 represent ventilation rates (Joo et al., 2014).

\subsection{2 $\mathrm{CO}_{2}$-balance method}

196 Barn AER by $\mathrm{CO}_{2}$-balance method was computed as the quotient of the $\mathrm{CO}_{2}$ production rate and the difference between the $\mathrm{CO}_{2}$ concentration at the outlets and the inlets. Barn AER by

$198 \mathrm{CO}_{2}$-balance method was computed as the quotient of the $\mathrm{CO}_{2}$ production rate (Eq. 3) and the 199 difference between the $\mathrm{CO}_{2}$ concentration at the outlets and the inlets (Eq. 5). Equation 4 was 200 used to adjust the daily $\mathrm{CO}_{2}$ production rate to hourly $\mathrm{CO}_{2}$ production rates based on hourly 201 mean relative animal cattle activity. The total $\mathrm{CO}_{2}$ production includes $\mathrm{CO}_{2}$ produced by the

202 animals and $\mathrm{CO}_{2}$ emitted from the manure. In general, most of $\mathrm{CO}_{2}$ in $\mathrm{NV}$ barn is from 203 respiration of the housed animals. The manure (urine and feces) and bedding material, however, 204 also produces some $\mathrm{CO}_{2}$ but this amount is usually less than $5 \%$ of the amount produced via 205 animal respiration. The $\mathrm{CO}_{2}$ production from the latter sources is thus usually neglected in the 206 mass balance model (Samer and Abuarab, 2014). Computations using Eq. (3), Eq. (4), and Eq. (5) 
assume ideal air-mixing inside the barn (Pedersen et al., 1998; CIGR, 2002; Blanes and Pedersen,

208 2005; Zhang et al., 2005):

209

$$
\begin{gathered}
C_{\text {prod }}=0.185 \phi^{*}{ }_{\text {tot }} / 1000 \\
A_{\mathrm{CO}_{2}}^{\prime}=\frac{\bar{A}_{\text {hourly }}}{\bar{A}_{\text {daily }}} \\
A E R_{\mathrm{CO}_{2}}=\frac{A_{C O_{2}}^{\prime} C_{\text {prod }}}{10^{-6}\left(C_{\text {out }}-C_{\text {in }}\right)}
\end{gathered}
$$

212 Where: $C_{\text {prod }}$ is the $\mathrm{CO}_{2}$ production $\left(\mathrm{m}^{3} \mathrm{~h}^{-1}\right)$ on a 24-h basis; 0.185 is a fixed $\mathrm{CO}_{2}$ production

213 rate $\left(0.185 \mathrm{~m}^{3} \mathrm{~h}^{-1} \mathrm{HPU}^{-1}\right)$; one heat production unit (HPU) is $1000 \mathrm{~W}$ of the total heat produced

214 by the animal at $20^{\circ} \mathrm{C} ; \phi^{*}$ tot is corrected total heat production for temperatures other than $20^{\circ} \mathrm{C}$

215 (W); $A_{\mathrm{CO}_{2}}^{\prime}$ is the coefficient for adjustment of the $24-\mathrm{h} \mathrm{CO}_{2}$ production rate for diurnal variation

216 based on relative animal activity; $\bar{A}_{\text {hourly }}$ is the respective hourly mean animal activities; $\bar{A}_{\text {daily }}$

217 is the daily mean animal activity; $A E R_{\mathrm{CO}_{2}}$ is the air exchange rate by $\mathrm{CO}_{2}$-balance method

$218\left(\mathrm{~h}^{-1}\right) ; C_{\text {in }}$ and $C_{\text {out }}$ are the $\mathrm{CO}_{2}$ concentrations ( $\mathrm{ppm}$ ) in the inlet and outlet air, respectively.

219 The corrected total heat production $\phi^{*}{ }_{\text {tot }}$ was calculated using Eq. (6) and (7) (CIGR, 220 1984, 2002; Blanes and Pedersen, 2005).

$$
\begin{gathered}
\phi_{t o t}=\phi_{L M}+\phi_{M Y}+\phi_{p}=5.6 m^{0.75}+22 Y+1.6 \times 10^{-5} d_{p}^{3} \\
\phi^{*}{ }_{t o t}=\phi_{t o t}\left(1+0.004\left(20-T_{\text {ind }}\right)\right)
\end{gathered}
$$

223 Where: $\phi_{t o t}$ is total heat production by the animals at $20^{\circ} \mathrm{C}(\mathrm{W}) ; \phi_{L M}$ is heat dissipation due to

224 maintenance of essential function (W); $\phi_{M Y}$ is heat dissipation due to milk yield (W); $\phi_{p}$ is heat 225 dissipation due to pregnancy (W); $m$ is body mass of the cow ( $\sim 675 \mathrm{~kg} \mathrm{cow}^{-1}$ in this study); $Y$ is 226 milk yield ( $\sim 30 \mathrm{~kg} \mathrm{cow}^{-1} \mathrm{~d}^{-1}$ in this study); $d_{p}$ is days of pregnancy; The heat dissipation due to 227 pregnancy is negligible and is usually ignored in Eq. (6) (Wang et al., 2006; Ngwabie et al.,

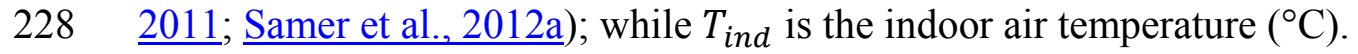

\subsection{Data Processing and Analysis}

231 The direct method was considered as the reference method in all the analyses in this paper. 232 Barn AER values lying outside of 1.5 IQR (interquartile range), during respective study periods, 
233 were designated outliers and were not used in subsequent analyses (Sancho et al., 2014; Joo et al.,

234 2015a). The lowest percentages of respective usable data compared to total data collected (i.e., 1-

$235 \mathrm{~h}$ averaging data processing) were $98 \%$ for direct method and $88 \%$ for $\mathrm{CO}_{2}$-balance method. To

236 determine the effect of temperature difference between indoor and outdoor, data were first sorted

237 with respect to temperature difference, from lowest to highest. The mean AER within $0.5^{\circ} \mathrm{C}$

238 intervals were then computed to reduce data points to a reasonable number for regression

239 analyses as well as for figure plotting purposes. In order to evaluate the effects of wind direction

240 and wind speed, data were classified into eight specific wind directions (N, NE, E, SE, S, SW, W,

241 and NW) and two wind speed regimes (low regime: $\leq 3 \mathrm{~m} \mathrm{~s}^{-1}$; high regime: $>3 \mathrm{~m} \mathrm{~s}^{-1}$ ). Analysis

242 of variance (ANOVA) and Fisher's LSD pairwise comparison tests were conducted to determine

243 the effects of wind direction and wind speed on barn AER at $\alpha=0.05$ significant level. These

244 statistical analyses were conducted using SAS v9.2 software package (SAS Institute, Cary, NC,

245 USA).

\section{Results and Discussion}

248 3.1 Measurement Periods, Barn, and Weather Information

249 The analyses in this paper were based on four different sets of data samples representing all

250 four seasons in a year. These data sets were selected based on the most stable operation periods

251 during each measurement campaign (i.e., no instrumentation, technical, or other management

252 problems). Details of the data collection periods, pertinent weather and curtains conditions are

253 shown in Table 1.

254 Temperature and wind speed not only varied across seasons but also fluctuated widely

255 (manifested in large standard deviations) during each continuous measurement period probably

256 because of large temporal variations in these parameters within these 7-d measurement periods.

257 The mean differences between average indoor and outdoor temperatures ranged from $0.5^{\circ} \mathrm{C}$ in

258 summer to $3.2^{\circ} \mathrm{C}$ in winter; suggesting that fully open sidewall curtains during summer improved

259 ventilation, allowing the indoor temperatures to approach the outdoor temperatures. The fully

260 closed curtains during winter, however, limited barn ventilation and thus kept indoor

261 temperatures significantly above outdoor temperatures. Although the average wind speed was 
262 higher in winter than in summer, the fully closed curtains were effective in limiting AER. Fig. 4 263 represents local average wind speeds and directions during the respective measurement periods.

264 The prevailing wind directions were southwest in March (winter) and May (spring), northwest in 265 July (summer), and north or southwest in September (autumn).

\subsection{Seasonal Variations of AER}

Air exchange rates by the $\mathrm{CO}_{2}$-balance method and direct method and the differences between the two measurement methods during the four measurement periods based on 24-h averaging are shown in Fig. 5. The AER varied significantly with season but were generally lower during cool seasons (March and September) and higher during warm seasons (May and July) (Fig. 5a). The mean AER, based on 24-hour averaging, ranged between 13 and $39 \mathrm{~h}^{-1}$ for all study periods and across these two methods. The standard minimum AER, in order to provide a safe and healthy environment (with respect to moisture, temperature, dust, pathogens, and gaseous contaminants levels) in mechanically ventilated (MV) dairy barns, range from $6 \mathrm{~h}^{-1}$ in winter to $60 \mathrm{~h}^{-1}$ in summer (Heber, 1990; Gooch, 2008). The AER for our NV study barn, therefore, always exceeded the standard minimum dairy barn ventilation requirements in cold weather but not during hot weather, indicating that NV barns, at this location, may need to be equipped with fans to enhance ventilation during hot weather.

280 The $\mathrm{CO}_{2}$-balance method, in general, resulted in the higher AER values compared to the direct method (Fig. 5b). The higher AER by the $\mathrm{CO}_{2}$-balance was attributed to the limitation of the applicable $\mathrm{CO}_{2}$ production model (Eq. 3). The $\mathrm{CO}_{2}$ production rate mean value of $0.185 \mathrm{~m}^{3} \mathrm{~h}^{-1}$ $283 \mathrm{hpu}^{-1}$ (CIGR, 2002), for example, may not be representative, for the herd of cows in this study 284 without some modification. The $\mathrm{CO}_{2}$ production rate needed to be adjusted to $0.178 \mathrm{~m}^{3} \mathrm{~h}^{-1} \mathrm{hpu}^{-1}$ 285 for our study barn based on 24-h averaging to yield AER comparable to direct method, which 286 was also in the 0.17 to $0.20 \mathrm{~m}^{3} \mathrm{~h}^{-1} \mathrm{hpu}^{-1}$ range reported in a previous study (Van Ouverkerk and 287 Pedersen, 1994). The latter adjustment of approximately $4 \%$ reflects the probable error which 288 arise from the assumption of negligible $\mathrm{CO}_{2}$ productions from manure and bedding materials, in

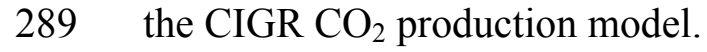


The $\mathrm{CO}_{2}$-balance method is impacted by factors that change with both time and space. Fig. 6

293 shows the effects of four different integration times, during data processing, on the performances

294 of the $\mathrm{CO}_{2}$-balance method. The shorter integration times (1, 2, and $\left.12 \mathrm{~h}\right)$ indicated wider

295 distribution or scatter of AER compared to the 24-h averaging. The correlation coefficient

296 between the $\mathrm{CO}_{2}$-balance method and the direct method also decreased with integration time.

297 These results are a reflection of the wide range of diurnal variations in the production of $\mathrm{CO}_{2}$ and

298 also demonstrated that the assumption of perfect air mixing, especially, at shorter averaging

299 times is suspect. The corresponding p-values of the paired t-test between AER by the $\mathrm{CO}_{2}{ }^{-}$

300 balance method and direct method were $<0.0001,<0.0001,0.0082$, and 0.1510 , at integration

301 times of 1, 2, 12, and $24 \mathrm{~h}$, respectively. The results further show that barn AER yielded by the

$302 \mathrm{CO}_{2}$-balance method based on 24-h average were not significantly different from those obtained

303 by direct method $(\mathrm{p}>0.05)$. This phenomenon is partly consistent with that reported in a

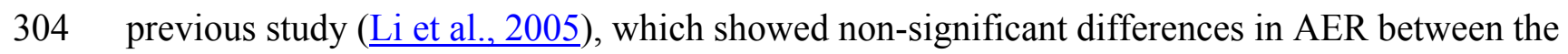

$305 \mathrm{CO}_{2}$-balance method and direct method for MV broiler houses with integrating times above $2 \mathrm{~h}$.

306 Although the 24-h averaged AER are more dependable for determining cumulative emissions,

307 with the $\mathrm{CO}_{2}$ balance, it is not possible to utilize these data to map diurnal variations of emission

308 rates since pollutant emissions and AER change widely in both time and space.

309 According to the previous literatures(CIGR, 2002; Blanes and Pedersen, 2005), relative

310 animal activity is a reliable parameter for determining diurnal variation of the $\mathrm{CO}_{2}$ production

311 rate. The barn AER obtained after adjusting the 1-h averaging $\mathrm{CO}_{2}$ production rate using relative

312 animal activity is shown in Fig. 7. The results show that, when this correction was applied, the

313 correlation coefficient between AER calculated by $\mathrm{CO}_{2}$-balance method and direct method was

314 less than before the adjustment. However, AER by $\mathrm{CO}_{2}$-balance method was relatively close to

315 the AER by direct method. Consequently, 1-h data averaging after adjustment for diurnal $\mathrm{CO}_{2}$

316 production rate using relative animal activity was used to analyze the effects of other pertinent

317 factors on the performances of the indirect method, hereafter, in this paper.

\subsection{Effects of Wind Speed and Wind Direction}

320 Local wind speeds during the four seasons fluctuated widely; ranging from 0.09 to $17.40 \mathrm{~m} \mathrm{~s}^{-1}$

321 although $88 \%$ of wind speeds were below $6 \mathrm{~m} \mathrm{~s}^{-1}$. Fig. 8a presents the variation of AER with 
322 wind speed for each of the two methods under northeasterly winds $\left(22.5^{\circ}-67.5^{\circ}\right)$. Barn AER 323 increased with wind speed $\left(\mathrm{R}^{2}\right.$ were 0.79 for the direct method and 0.31 for the $\mathrm{CO}_{2}$-balance 324 method). This observation is consistent with ventilation theorem and other empirical data (Wu et 325 al., 2012). These results also revealed the lower precision of the $\mathrm{CO}_{2}$-balance method compared 326 with the direct method, due to the variability or noise associated with the $\mathrm{CO}_{2}$-balance method.

327 Fig $8 \mathrm{~b}$, on the other hand, shows that the increase in wind speed had some, though limited, 328 influence on the differences in AER between $\mathrm{CO}_{2}$-balance and direct methods $\left(\mathrm{R}^{2}=0.21\right)$. One 329 possible reason for this is that increased wind speed results in higher volatilization of $\mathrm{CO}_{2}$ from 330 manure, which may further distort the $\mathrm{CO}_{2}$ productions by the animals in the respective models.

331 Generally, high wind speeds are expected to enhance barn AER. As a result, the temperature 332 differences between air inside and outside the barn, therefore, should decrease concurrently with 333 an increase in wind speed. These stipulations are strongly $\left(\mathrm{R}^{2}=0.78\right)$ supported by the analyses 334 presented in Fig. 9. Although temperature differences provide buoyant force that induces air 335 exchange in livestock buildings, wind speed is evidently the stronger factor governing AER 336 compared with temperature difference (Barrington et al., 1994; Zhang et al., 2005; Norton et al., 337 2009).

338 The relationships between AER determined by each of the two methods and wind direction as 339 well as relationship between wind speed and wind direction are both presented in Fig. 10. The 340 barn AER was strongly dependent on wind direction regardless of methods adopted. The mean 341 barn AER by direct method for northerly winds $\left(41.4 \mathrm{~h}^{-1}\right.$ at the mean wind speed of $\left.1.26 \mathrm{~m} \mathrm{~s}^{-1}\right)$, 342 for instance, was 1.33 times greater than for westerly winds $\left(31.2 \mathrm{~h}^{-1}\right.$ at the mean wind speed of $3434.60 \mathrm{~m} \mathrm{~s}^{-1}$ ). These results are best explained by the wind incident angle (De Paepe et al., 2013).

344 The wind was normal or perpendicular to the long north-wall of the barn, for northerly winds; 345 while for westerly winds, the west end-wall receiving the wind is shorter, resulting in less 346 airflow into the building. These results reveal or confirm why orientation of NV buildings must 347 always take into account prevailing wind direction in order to optimize natural ventilation.

348 The more rigorous analysis of variance (ANOVA) was performed to evaluate, together, the 349 effects of wind speed and wind direction on barn AER and also the AER differences between $350 \mathrm{CO}_{2}$-balance and direct methods with respect to eight wind-directions and two wind-speeds 351 regimes (Table 2). The ANOVA indicated no significant interaction between wind direction and 
352 wind speed with regard to either AER estimated by $\mathrm{CO}_{2}$-balance method $(\mathrm{p}=0.07)$ or AER

353 differences between $\mathrm{CO}_{2}$-balance method and direct method $(\mathrm{p}=0.32)$. Individually, wind speed

354 had significant effect on both barn AER obtained by the $\mathrm{CO}_{2}$-balance method $(\mathrm{p}<0.05)$ as well

355 as on AER differences between $\mathrm{CO}_{2}$-balance method and direct method $(\mathrm{p}<0.05)$. Tukey's

356 pairwise comparison test showed that low wind speed regime resulted in lower AER as expected

357 but resulted in higher AER difference between the two methods.

358 Wind direction also had significant effect on barn AER obtained by the $\mathrm{CO}_{2}$-balance method $359(\mathrm{p}<0.05)$ and also on the AER differences between the two methods $(\mathrm{p}<0.05)$ as shown in 360 Table 2. In general, barn AER from the $\mathrm{CO}_{2}$-balance method for northerly winds (NW, N, NE) 361 were significantly higher than for southerly winds (SW, S, SE). The latter was attributed to more 362 windbreaks or obstacles sheltering the south wall compared to the north wall. Westerly winds 363 also resulted in higher barn AER than the easterly winds due to higher wind speed for west 364 winds compared to east winds. Effectively, therefore, the north-westerly winds thus indicated 365 higher barn AER rates than south-easterly winds. The SE and NE winds resulted in 366 underestimation of AER by the $\mathrm{CO}_{2}$-balance method, while all other winds indicated 367 overestimation of barn AER. The $\mathrm{E}$ and SE winds indicated significantly lower differences 368 between the two methods compared to $\mathrm{W}$ and NW winds. The lower frequency and lower speed 369 of easterly winds compared to other winds are the only discernable differences, which may 370 explain the preceding results (Fig. 4 and Table 2). The prevailing wind directions, during the 371 measurements campaign periods were SW in March and May, NW in July, and N or SW in 372 September.

\subsection{Effect of Differences in Indoor-Outdoor $\mathrm{CO}_{2}$ Concentrations and Temperatures}

375 The effects of $\mathrm{CO}_{2}$ concentration and temperature differences between indoor and outdoor air 376 on barn AER by the $\mathrm{CO}_{2}$-balance method are presented in Fig. 11. Except during milking periods 377 ( $6 \%$ of time), the $\mathrm{CO}_{2}$ concentration of indoor air was usually higher than that of outdoor air. 378 The differences in barn AER between the two methods (Fig. 11a) shows that the differences 379 between $\mathrm{CO}_{2}$-balance method and direct method were higher or more erratic when $\mathrm{CO}_{2}$ 380 concentration differences between indoor and outdoor air were less than $70 \mathrm{ppm}$. 
The differences between indoor and outdoor temperatures varied with seasons. Indoor temperatures were usually higher than outdoor temperatures. Lower indoor temperatures were rare and often occurred during warm periods (July and May). Indoor and outdoor temperature differences, in general, were larger than $2.5^{\circ} \mathrm{C}$ during cool periods (March and September) indicating lower barn AER. The differences in barn AER by the $\mathrm{CO}_{2}$-balance method and direct method were greater or more erratic at lower temperature differences, especially below $0^{\circ} \mathrm{C}$ (Fig. 387 11b).

These results agree with those reported in previous studies. Pedersen et al. (1998) research concluded that the $\mathrm{CO}_{2}$-balance method was unreliable when either the $\mathrm{CO}_{2}$ concentrations differences were less than $200 \mathrm{ppm}$ or the differences in temperatures were less than $2^{\circ} \mathrm{C}$, between indoor and outdoor air. These researchers noted that random or erratic variations in AER estimated by the $\mathrm{CO}_{2}$ balance equation were greater at these low concentrations and temperatures differences regimes. In general, conditions of excellent ventilation for $\mathrm{NV}$ animal houses result in smaller or narrower concentrations and temperatures differences between air inside and outside the barn, which (sometimes) may result in relatively larger errors. The results suggest that the $\mathrm{CO}_{2}$-balance method is more reliable in estimating AER for poorly ventilated $\mathrm{NV}$ dairy barns (i.e. during periods of poor ventilation) or for controlled ventilation systems found in MV dairy barns.

\subsection{Effect of Milking Time}

401 The cows in the study barn were milked twice a day starting at approximately 4:00 am and $4024: 00 \mathrm{pm}$. In each session, all cows in one of the two pens were moved out to the milking parlor 403 and returned to their respective pens in one hour. In the second hour, the cows in the other pen 404 were then moved out for milking. Because the indirect methods depend highly on physiological 405 parameters, this movement of the cows for milking inherently affects the AER measurements by the $\mathrm{CO}_{2}$-balance method. Significant errors in computing AER and thus the emission rates of 407 pollutants may occur if cow movements during milking periods are not accounted for in the 408 computations. Fig. 12 represents barn AER determined by the two methods for a typical day in 409 March. Evidently, the AER during milking periods were significantly overestimated by the $\mathrm{CO}_{2}$ 410 balance method compared to steady AER by the direct method. 
411 In general, $\mathrm{CO}_{2}$ production decrease with decrease of cow numbers in the barn, which implies

412 narrower or less differences in the concentrations of $\mathrm{CO}_{2}$ between indoor and outdoor air.

413 Effectively, random errors are significantly exaggerated. For example, the differences between

414 indoor and outdoor $\mathrm{CO}_{2}$ levels are the denominators in equation (4), for computation of AER

415 using $\mathrm{CO}_{2}$ mass balance. A unit of random error will have a greater effect when these differences

416 are smaller compared to when they are larger, which skews or distorts AER. Previous research

417 attributed these erratic AER to increased animal activity in the building, disturbance of air flow

418 pattern and low differences in indoor outdoor concentrations (Marik and Levin, 1996; Snell et al.,

419 2003; Wang et al., 2006; Ngwabie et al., 2009). The current study points to the differences

420 between indoor and outdoor air $\mathrm{CO}_{2}$ concentrations as the major culprit.

421 Table 3, for example, presents the proportion of acceptable AER based on hourly means

422 during $28 \mathrm{~d}$ of measurements using the daily 4:00 pm milking session. The means and standard

423 deviations of barn AER by direct method for each day were considered as the reference statistics

424 for computing the proportions presented in Table 3. The AER determined by $\mathrm{CO}_{2}$-balance

425 method were considered outliers when they fell outside of three standard deviations from the

426 mean. The acceptable data with the $\mathrm{CO}_{2}$-balance method were only 52\% during milking time.

427 Clearly, AER and emissions data collected using $\mathrm{CO}_{2}$ balance method during milking time may

428 be unreliable and should be discarded or interpreted or used cautiously.

\section{Conclusions}

431 Air exchange rates for a NV dairy barn were determined using an indirect method (the $\mathrm{CO}_{2}$ -

432 balance method) and a direct method. The effects of pertinent factors on $\mathrm{CO}_{2}$-balance method

433 were also evaluated. The following conclusions were based on data obtained in these studies:

434 (1) The mean AER in barn ranged from 13 to $39 \mathrm{~h}^{-1}$ across all study periods and methods. The

$435 \mathrm{CO}_{2}$-balance method, in general, tended to overestimate the AER. The $\mathrm{CO}_{2}$ production rate,

436 in the current study, was estimated at $0.178 \mathrm{~m}^{3} \mathrm{~h}^{-1} \mathrm{hpu}^{-1}$ using the 24-h data averaging.

437 (2) Barn AER obtained by $\mathrm{CO}_{2}$-balance method with integration time of $24 \mathrm{~h}$ were not

438 significantly different from those obtained with direct method. Shorter integration times $(1,2$,

439 and $12 \mathrm{~h}$ ) resulted in significantly different AER. 
(3) Barn AER increased with wind speed irrespective of the measurement methods adopted. The differences between the $\mathrm{CO}_{2}$-balance and direct methods were significantly affected by wind speed with higher wind speed regime indicating significantly lower differences than lower wind speed regime.

(4) The differences between the $\mathrm{CO}_{2}$-balance and direct method were also significantly affected by wind direction. The north-westerly winds indicated higher barn AER than south-easterly winds. The SE and NE winds resulted in underestimation of AER by the $\mathrm{CO}_{2}$-balance method, while all other winds indicated overestimation of barn AER. The E and SE winds

\section{Acknowledgement}

The authors acknowledge partial financial support from the Agricultural Air Research Council, the National Dairy Board, USDA-NRCS through grant \#69-3A75-11-210, and the Washington State Agricultural Research Center. Authors also acknowledge the cooperation and assistance from the anonymous owners of the dairy on which this study was conducted.

\section{References}

Andonov, K., Daskalov, P., Martev, K., 2003. A new approach to controlled natural ventilation of livestock buildings. Biosys. Eng. 84, 91-100.

Barrington, S., Zemanchik, N., Choiniere, Y., 1994. Orienting livestock shelters to optimize natural summer ventilation. Trans. ASAE (USA).

Blanes, V., Pedersen, S., 2005. Ventilation flow in pig houses measured and calculated by carbon dioxide, moisture and heat balance equations. Biosys. Eng. 92, 483-493.

Chepete, H.J., Xin, H., 2004. Ventilation rates of a laying hen house based on new vs. old heat and moisture production data. Appl. Eng. Agric. 20, 835.

CIGR, 1984. Climatization of animal houses, in: Report of working group, C. (Ed.), Scottish Farm Buildings Investigation Unit, Aberdeen.

CIGR, 2002. Climatization of Animal Houses - Heat and Moisture Production at Animal and House Level, in: Group, t.R.o.C.W. (Ed.), Horsens, Denmark. 
De Paepe, M., Pieters, J.G., Cornelis, W.M., Gabriels, D., Merci, B., Demeyer, P., 2013. Airflow measurements in and around scale-model cattle barns in a wind tunnel: Effect of wind incidence angle. Biosys. Eng. 115, 211-219.

Flourentzou, F., Van der Maas, J., Roulet, C.-A., 1998. Natural ventilation for passive cooling: measurement of discharge coefficients. Energy Build. 27, 283-292.

Gooch, C., 2008. Dairy freestall barn design-a northeast perspective, Ninth Annual Fall Dairy Conference. Cornell Pro-Dairy Program.

Heber, A., 1990. Mechanical ventilating systems for livestock housing. MWPS-32. Ames, Iowa: Iowa State University, Midwest Plan Service.

Joo, H., Ndegwa, P., Heber, A., Bogan, B., Ni, J.-Q., Cortus, E., Ramirez-Dorronsoro, J., 2014. A direct method of measuring gaseous emissions from naturally ventilated dairy barns. Atmos. Environ. 86, 176-186.

Joo, H., Ndegwa, P., Heber, A., Ni, J.-Q., Bogan, B., Ramirez-Dorronsoro, J., Cortus, E., 2015a. Greenhouse gas emissions from naturally ventilated freestall dairy barns. Atmos. Environ. 102, 384392.

Joo, H., Ndegwa, P., Heber, A., Ni, J.-Q., Cortus, E., Ramirez-Dorronsoro, J., Bogan, B., 2015b. Ammonia and hydrogen sulfide concentrations and emissions for naturally ventilated freestall dairy barns. Trans. ASABE Unpublished results.

Kiwan, A.K., Berg, W., Brunsch, R., Özcan, S., Müller, H.-J., Gläser, M., Fiedler, M., Ammon, C., Berckmans, D., 2012. Tracer gas technique, air velocity measurement and natural ventilation method for estimating ventilation rates through naturally ventilated barns. Agricultural Engineering International: CIGR Journal 14, 22-36.

Li, H., Xin, H., Liang, Y., Gates, R., Wheeler, E., AJ, H., 2005. Comparison of direct vs. indirect ventilation rate determinations in layers barns using manure belts. Trans. ASAE 48(1), 367-372.

Marik, T., Levin, I., 1996. A new tracer experiment to estimate the methane emissions from a dairy cow shed using sulfur hexafluoride (SF6). Global Biogeochem. Cycles 10, 413-418.

Ngwabie, N., Jeppsson, K.-H., Gustafsson, G., Nimmermark, S., 2011. Effects of animal activity and air temperature on methane and ammonia emissions from a naturally ventilated building for dairy cows. Atmos. Environ. 45, 6760-6768.

Ngwabie, N., Jeppsson, K.-H., Nimmermark, S., Swensson, C., Gustafsson, G., 2009. Multi-location measurements of greenhouse gases and emission rates of methane and ammonia from a naturallyventilated barn for dairy cows. Biosys. Eng. 103, 68-77.

Ni, J.-Q., Heber, A.J., 2010. An on-site computer system for comprehensive agricultural air quality research. Comput. Electron. Agric. 71, 38-49.

Norton, T., Grant, J., Fallon, R., Sun, D.-W., 2009. Assessing the ventilation effectiveness of naturally ventilated livestock buildings under wind dominated conditions using computational fluid dynamics. Biosys. Eng. 103, 78-99.

Ogink, N., Mosquera, J., Calvet, S., Zhang, G., 2013. Methods for measuring gas emissions from naturally ventilated livestock buildings: developments over the last decade and perspectives for improvement. Biosys. Eng. 116, 297-308.

Ozcan, S.E., Vranken, E., Berckmans, D., 2007. An overview of ventilation rate measuring and modelling techniques through naturally ventilated buildings, in: Monteny, G.-J., et al (Ed.), Ammonia Emissions in Agriculture. Wageningen Academic Publishers, The Netherlands, pp. 351-353.

Pedersen, S., Takai, H., Johnsen, J.O., Metz, J., Groot Koerkamp, P., Uenk, G., Phillips, V., Holden, M., Sneath, R., Short, J., 1998. A comparison of three balance methods for calculating ventilation rates in livestock buildings. J. Agr. Eng. Res. 70, 25-37.

Samer, M., Ammon, C., Loebsin, C., Fiedler, M., Berg, W., Sanftleben, P., Brunsch, R., 2012a. Moisture balance and tracer gas technique for ventilation rates measurement and greenhouse gases and ammonia emissions quantification in naturally ventilated buildings. Build. Environ. 50, 10-20.

Samer, M., Berg, W., Fiedler, M., von Bobrutzki, K., Ammon, C., Sanftleben, P., Brunsch, R., 2012b. A comparative study among $\mathrm{H}_{2} \mathrm{O}$-balance, heat balance, $\mathrm{CO} 2$-balance and radioactive tracer gas 
technique for airflow rates measurement in naturally ventilated dairy barns, Proceedings of the Ninth International Livestock Environment Symposium (ASABE ILES IX), pp. 8-12.

Samer, M., Müller, H.-J., Fiedler, M., Berg, W., Brunsch, R., 2014. Measurement of ventilation rate in livestock buildings with radioactive tracer gas technique: theory and methodology. Indoor Built Environ. 23, 692-708.

Sancho, J., Martínez, J., Pastor, J., Taboada, J., Piñeiro, J., García-Nieto, P.J., 2014. New methodology to determine air quality in urban areas based on runs rules for functional data. Atmos. Environ. 83, 185192.

Snell, H., Seipelt, F., Van den Weghe, H., 2003. Ventilation rates and gaseous emissions from naturally ventilated dairy houses. Biosys. Eng. 86, 67-73.

Van Ouverkerk, E., Pedersen, S., 1994. Application of the carbon dioxide mass balance method to evaluate ventilation rates in livestock buildings, Proc. XII CIGR'94, Italy, pp. 516-529.

Wang, C., Li, B., Zhang, G., Rom, H.B., Strøm, J.S., 2006. Model estimation and measurement of ammonia emission from naturally ventilated dairy cattle buildings with slatted floor designs. J. Air Waste Manage. Assoc. 56, 1252-1259.

Wu, W., Zhai, J., Zhang, G., Nielsen, P.V., 2012. Evaluation of methods for determining air exchange rate in a naturally ventilated dairy cattle building with large openings using computational fluid dynamics (CFD). Atmos. Environ. 63, 179-188.

Xin, H., Li, H., Gates, R.S., Overhults, D.G., Earnest Jr, J.W., 2009. Use of CO2 concentration difference or $\mathrm{CO} 2$ balance to assess ventilation rate of broiler houses. Trans. ASABE 52, 1353.

Zhang, G., Strøm, J.S., Li, B., Rom, H.B., Morsing, S., Dahl, P., Wang, C., 2005. Emission of ammonia and other contaminant gases from naturally ventilated dairy cattle buildings. Biosys. Eng. 92, 355364. 


\section{List of Figures}

550 Fig. 1 An aerial view of the research site and study barn (B2).

551 Fig. 2 (a) External and (b) internal views of the study dairy barn (B2).

552 Fig. 3 Layout of the barns, on-farm instrument shelter (OFIS), and monitoring locations: (a) end 553 view; (b) plan view; (c) side view.

554 Fig. 4 Prevailing wind speeds and directions during the four measurement periods.

555 Fig. 5 a) Air exchange rates (AER) by the two methods based on 24-h data averaging b) the 556 differences in air exchange rates $(\triangle \mathrm{AER})$ between $\mathrm{CO}_{2}$-balance method and direct method 557 based on the 24-h data averaging

558 Fig. 6 Effect of integration time on computation of AER using $\mathrm{CO}_{2}$-balance method.

559 Fig. 7 Effect of adjustment by activity on the air exchange rates (AER) by $\mathrm{CO}_{2}$-balance method $560 \quad$ based on the 1-h averaging processes.

561 Fig. 8 (a) Relationships between AER and wind speed for northeasterly winds $\left(22.5^{\circ}-67.5^{\circ}\right)$, and 562 (b) differences in AER ( $\triangle \mathrm{AER}$ ) between $\mathrm{CO}_{2}$-balance method and direct method at the same 563 wind condition.

564 Fig. 9 Variation of temperature difference $(\Delta \mathrm{T})$ between indoor and outdoor air with wind speed. 565 Fig. 10 a) Relationships between AER determined by two methods and wind directions and also 566 b) relationships between wind speeds and wind directions.

567 Fig. 11 Effect of a) $\mathrm{CO}_{2}$ concentration difference $\left(\Delta \mathrm{CCO}_{2}\right)$ and b) temperature difference $(\Delta \mathrm{T})$ on $568 \quad \mathrm{CO}_{2}$-balance method.

569 Fig. 12 Diurnal AER by direct method (-) and $\mathrm{CO}_{2}$-balance method (- - -). 


\section{$571 \quad$ List of Tables}

572 Table 1 Data collection periods and environmental conditions.

573 Table 2 Analysis of variance between hourly means of AER based on the $\mathrm{CO}_{2}$-balance method 574 and AER difference $(\triangle \mathrm{AER})$ between $\mathrm{CO}_{2}$-balance method and direct method determined 575 with respect to eight wind directions and two wind speed regimes (high and low).

576 Table 3 Proportion of acceptable AER during the 4 to $6 \mathrm{pm}$ milking time based on $28 \mathrm{~d}$ mean 577 hourly data. 
579 Fig. 1 An aerial view of the research site and study barn (B2) (Joo et al., 2014).

580

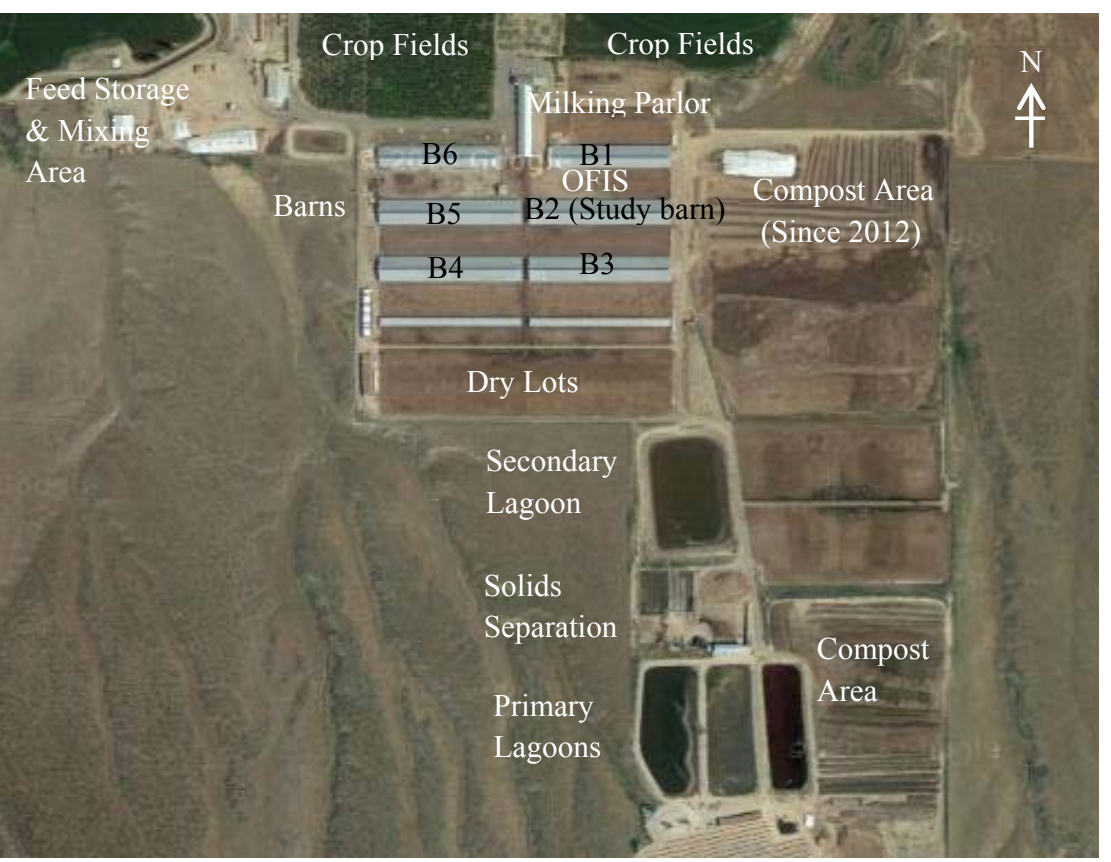

581

582 
583 Fig. 2 (a) External and (b) internal views of the study dairy barn (B2).

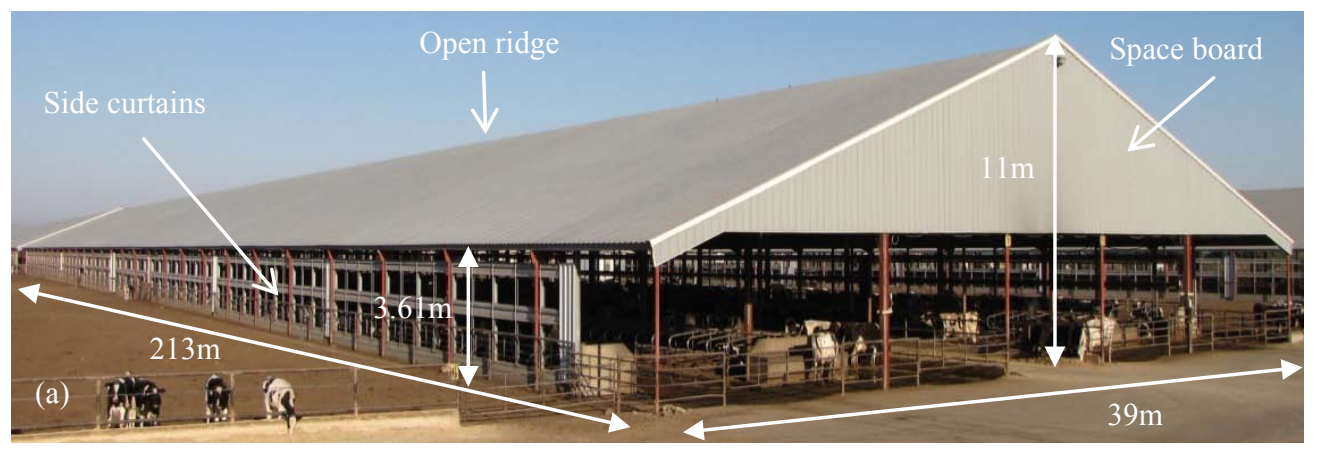

584

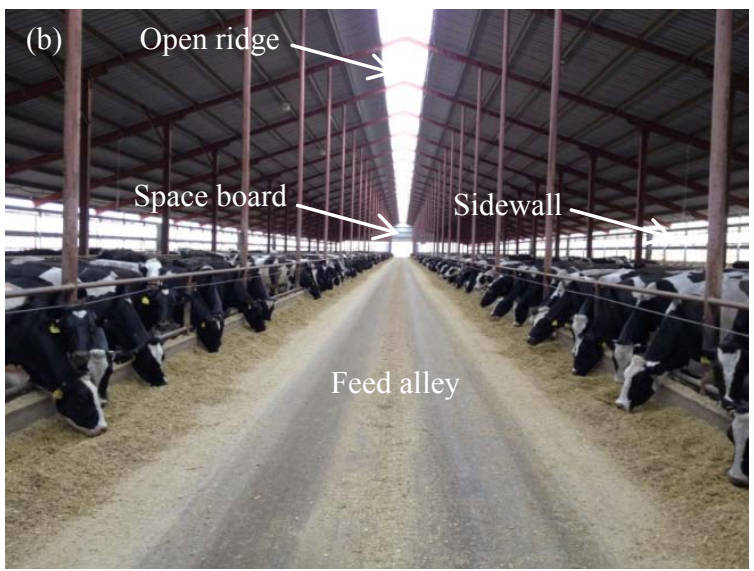

586 
587 Fig. 3 Layout of the barns, on-farm instrument shelter (OFIS), and monitoring locations: (a) end view; (b) 588 plan view; (c) side view (none of the views is drawn to scale).

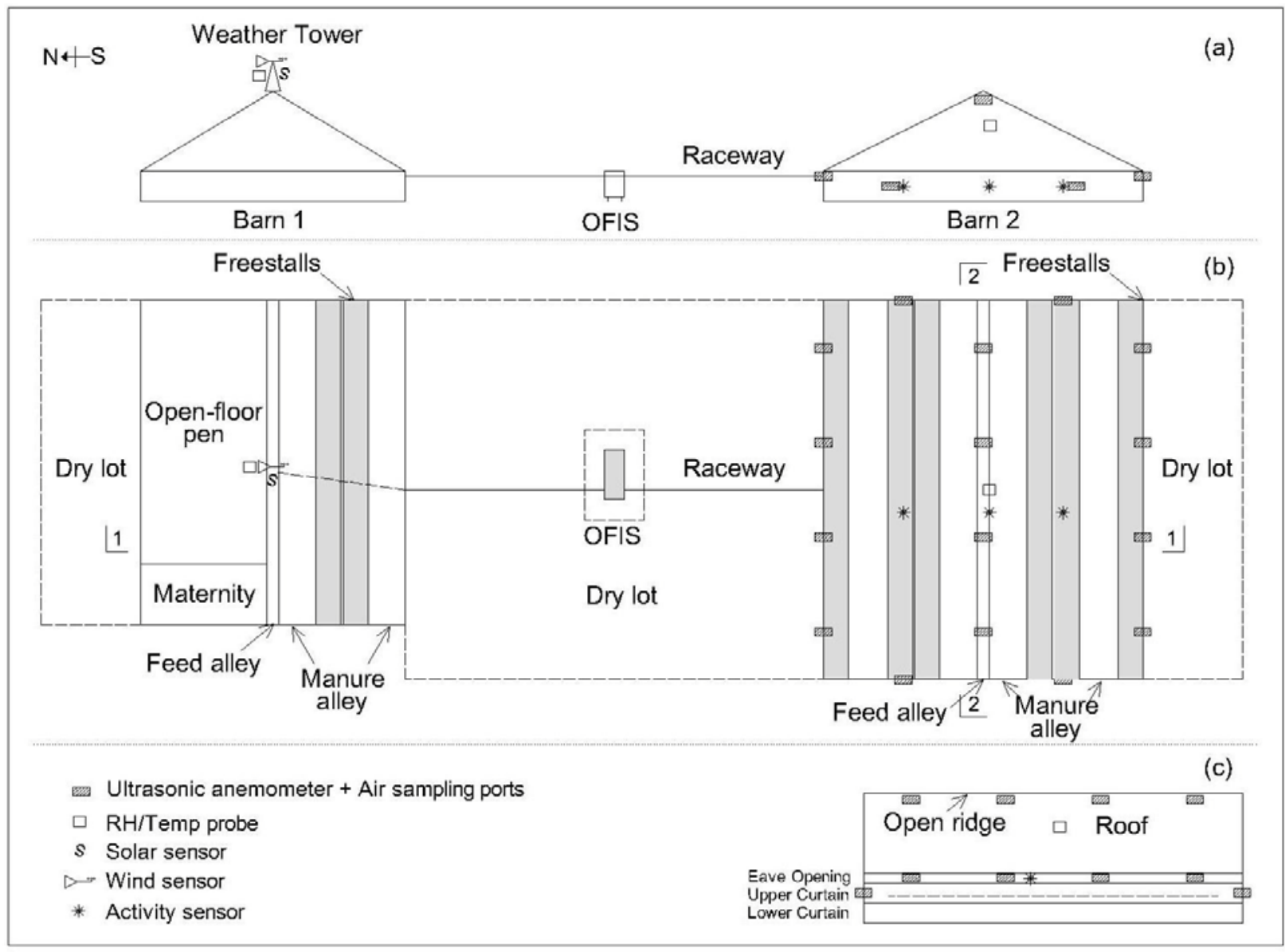


591 Fig. 4 Prevailing wind speeds and wind directions during the four measurement periods.

592

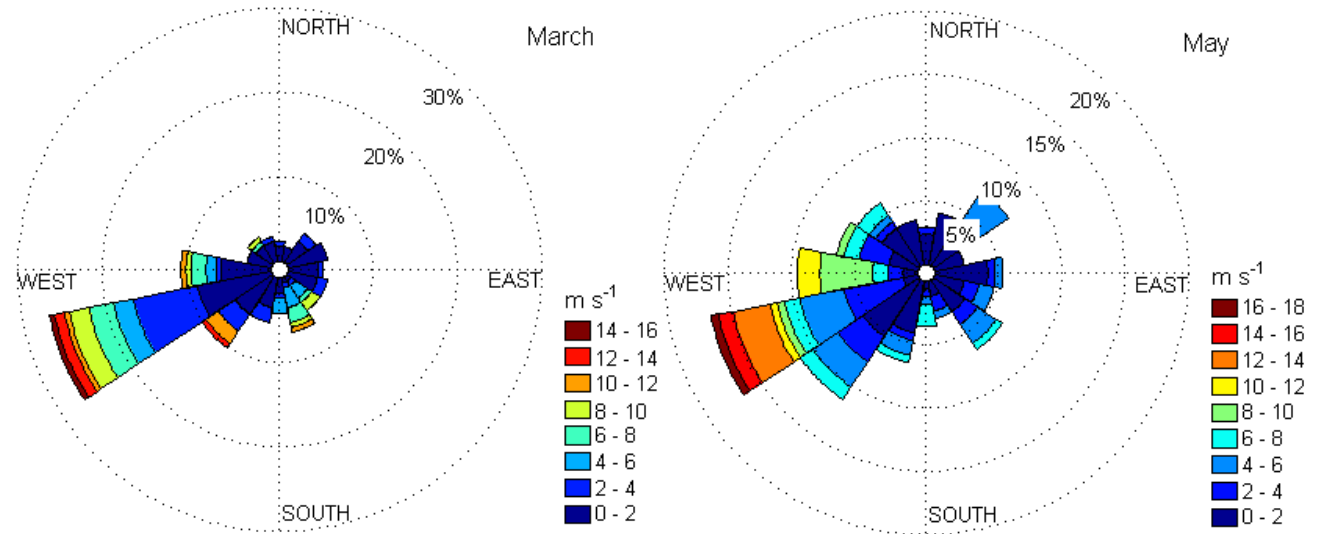

593

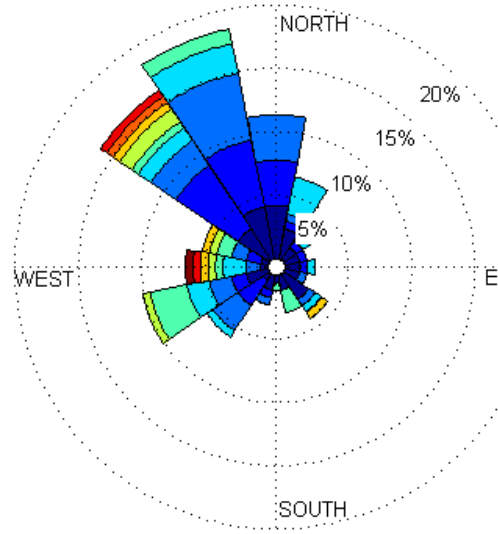

July
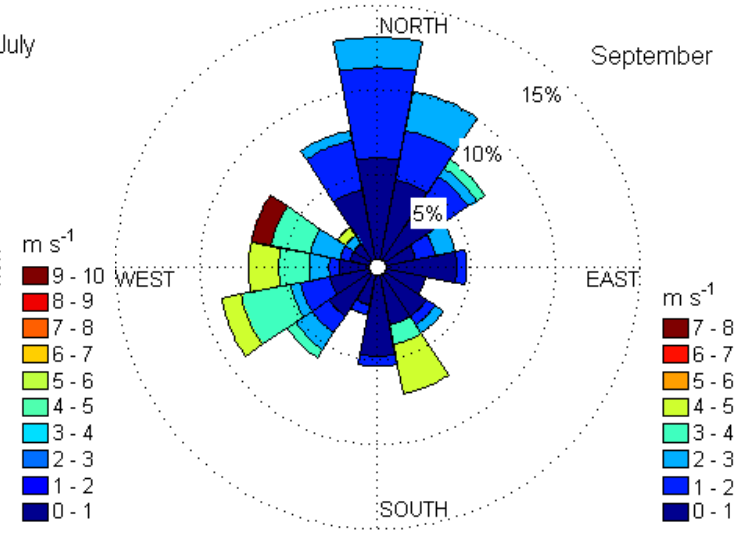

594 
595 Fig.5 a) Air exchange rates (AER) by the two methods based on 24-h data averaging b) the differences in 596 air exchange rates $(\triangle \mathrm{AER})$ between $\mathrm{CO}_{2}$-balance method and direct method based on the 24-h data 597 averaging (solids dots represent means; lines dividing the boxes show medians; the top and bottom of box 598 plots indicate first quartiles (Q1) and third quartiles (Q3), respectively; while the upper and under 599 whiskers indicate the maximum and minimum values within 1.5 times the interquartile range, 600 respectively).

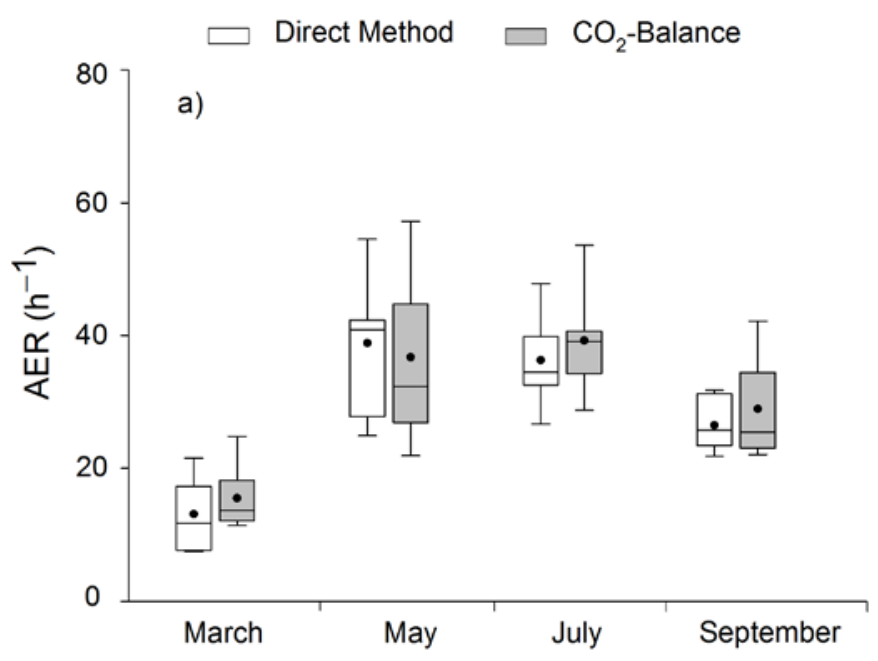

601

Study periods

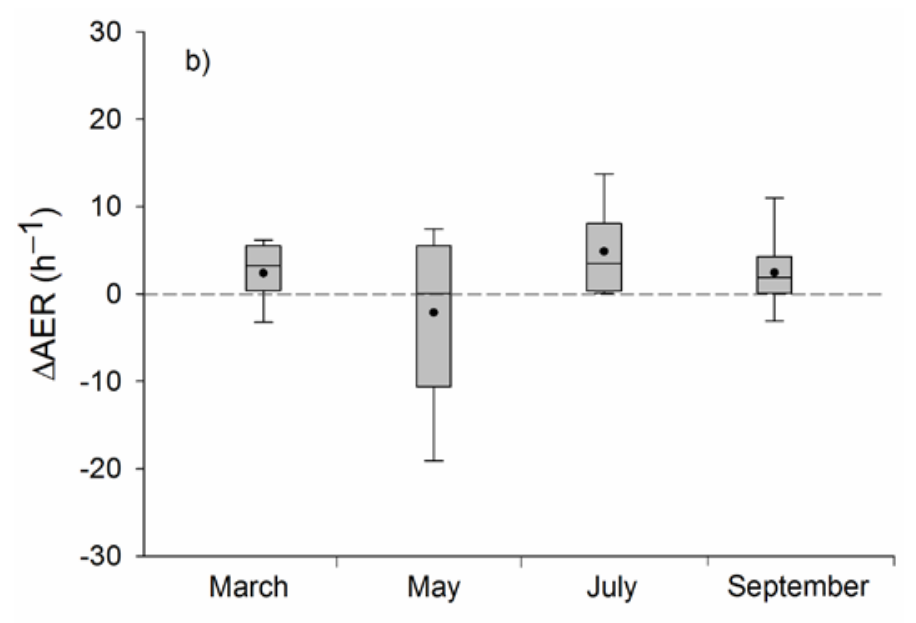

602

Study periods

603 
604 Fig. 6 Effect of integration time on computation of AER using $\mathrm{CO}_{2}$-balance method.
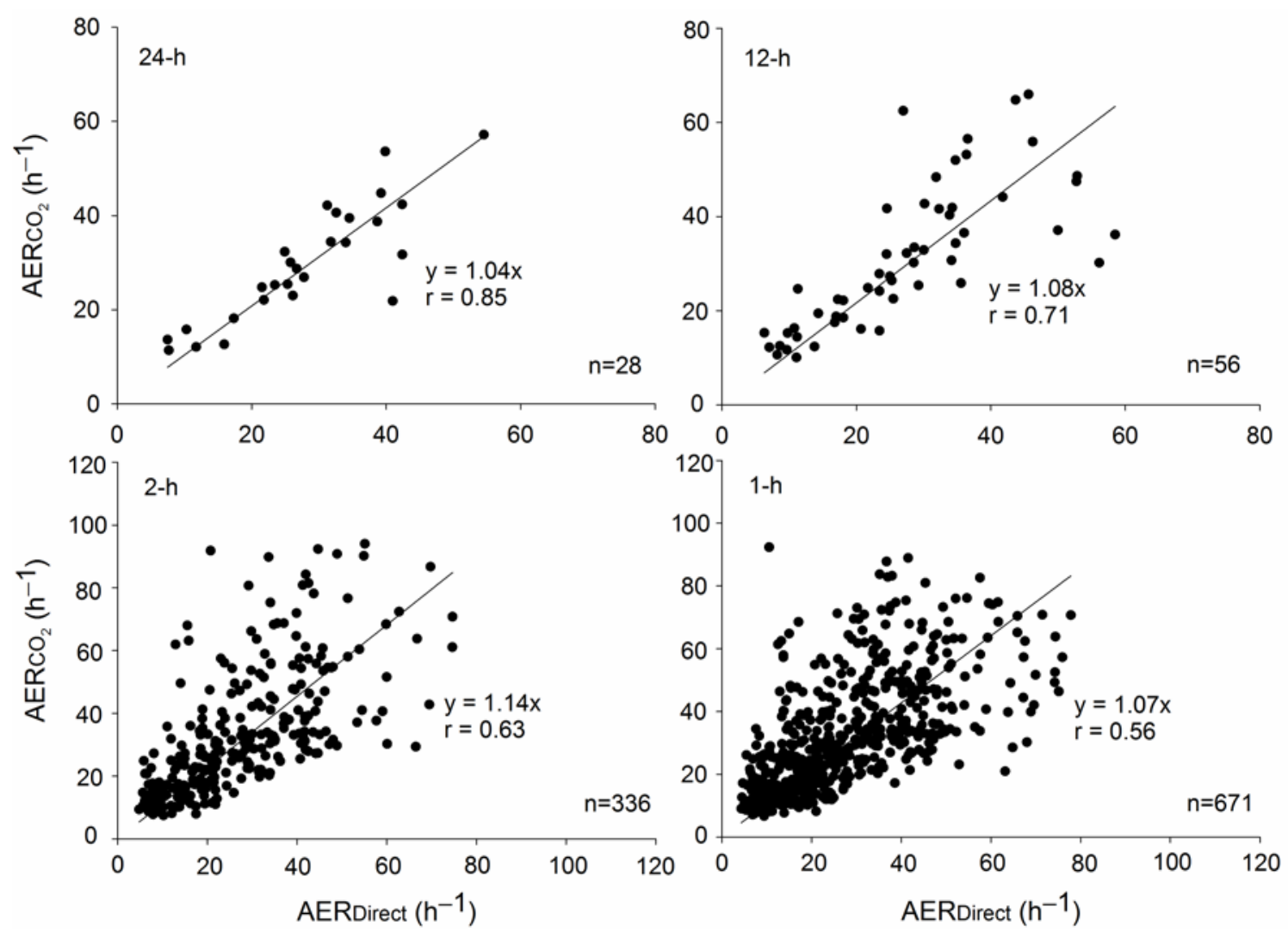

606 
607 Fig.7 Effect of adjustment by activity on the air exchange rates (AER) by $\mathrm{CO}_{2}$-balance method based on 608 the 1-h averaging processes.

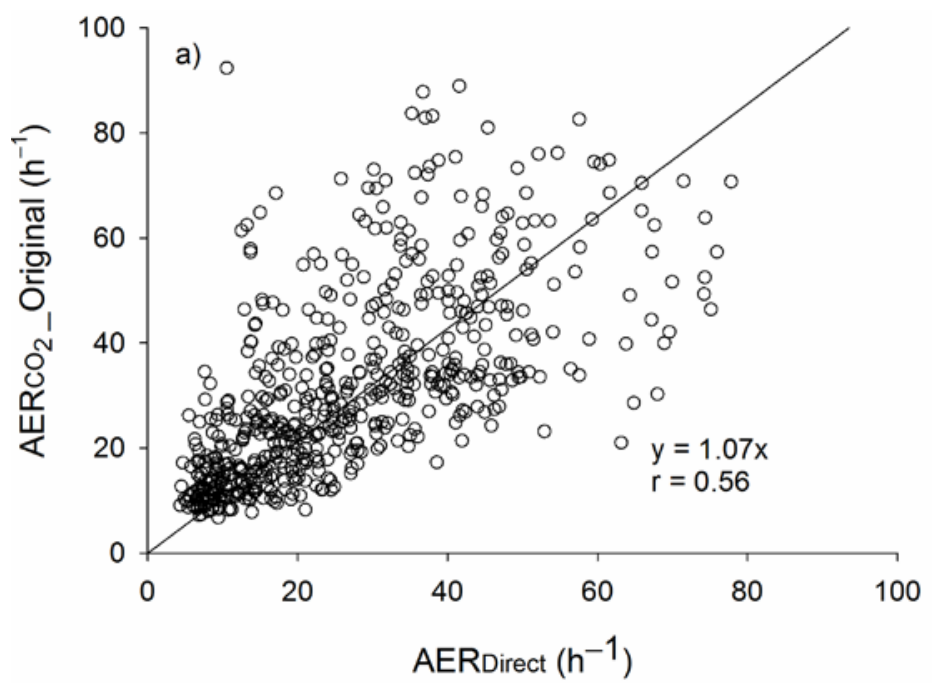

609

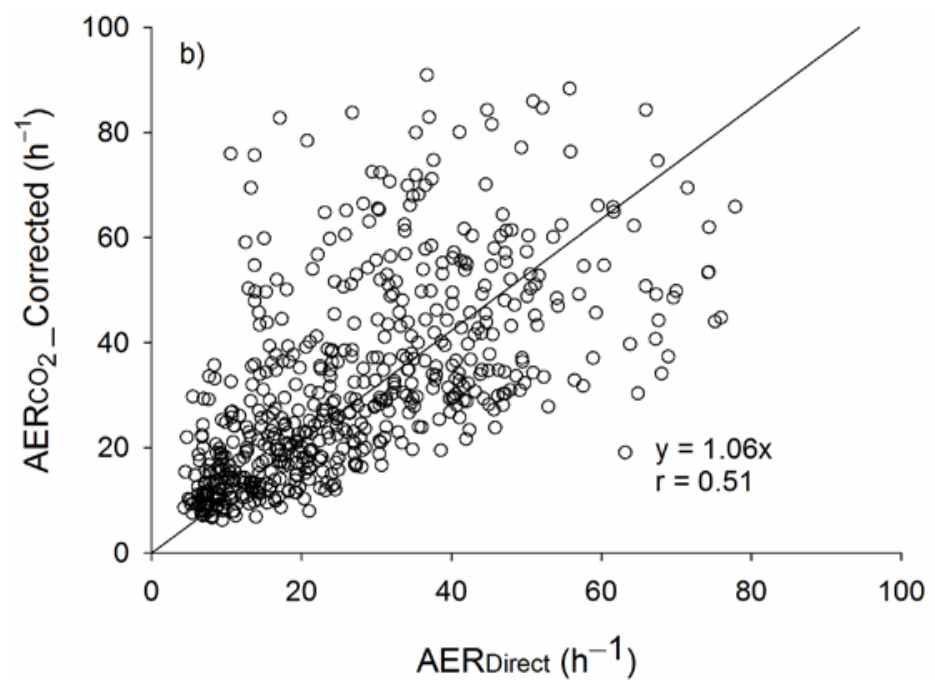

610

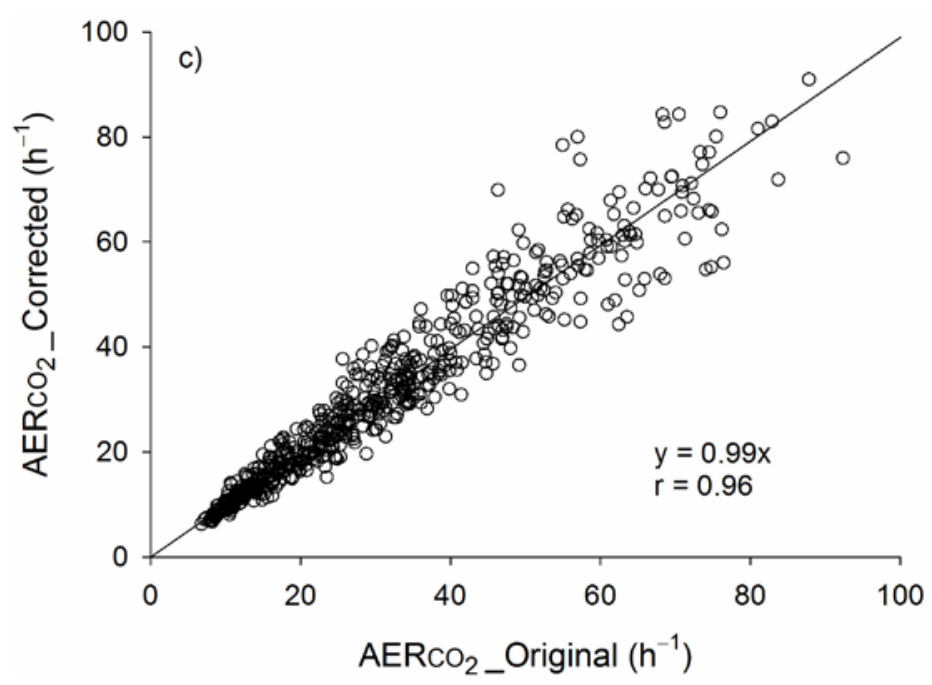

611 
612 Fig. 8 (a) Relationships between AER and wind speed for northeasterly winds $\left(22.5^{\circ}-67.5^{\circ}\right)$, and (b)

613 differences in AER ( $\triangle \mathrm{AER}$ ) between $\mathrm{CO}_{2}$-balance method and direct method at the same wind condition.

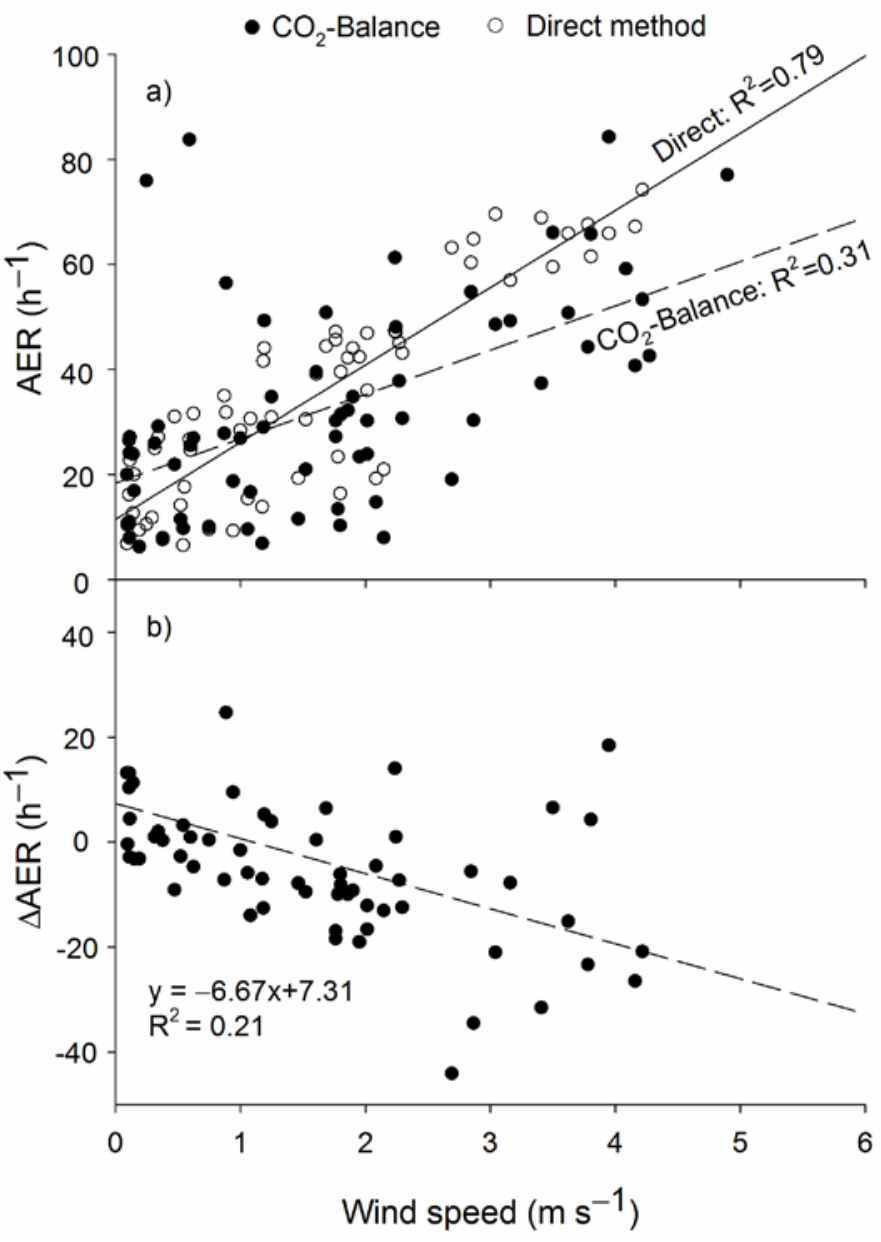

615 
616 Fig. 9 Variation of temperature difference $(\Delta \mathrm{T})$ between indoor and outdoor air with wind speed.

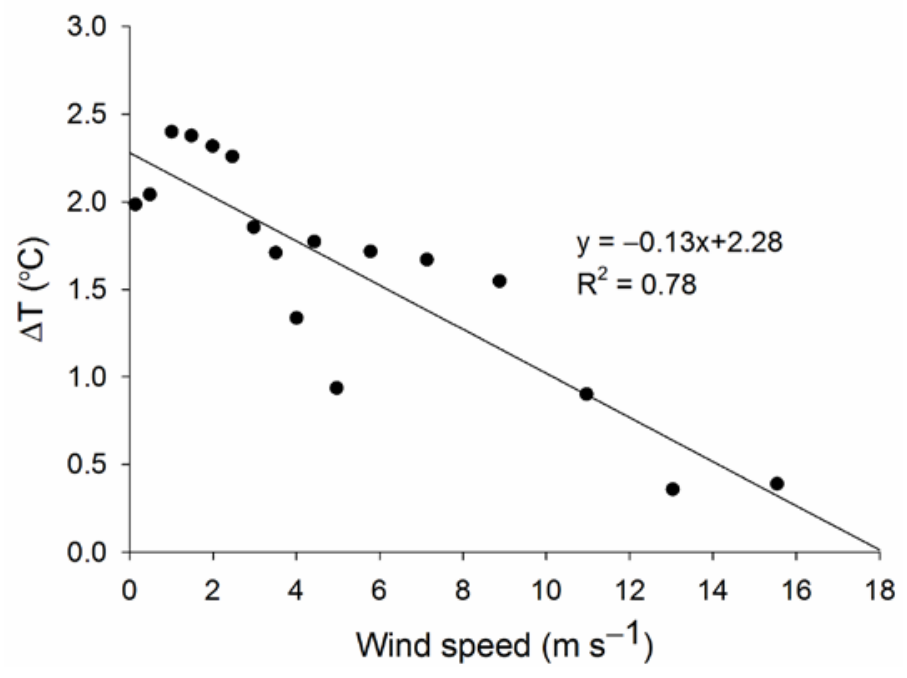


619 Fig. 10 a) Relationships between AER determined by two methods and wind directions and also b) 620 relationships between wind speeds and wind directions.

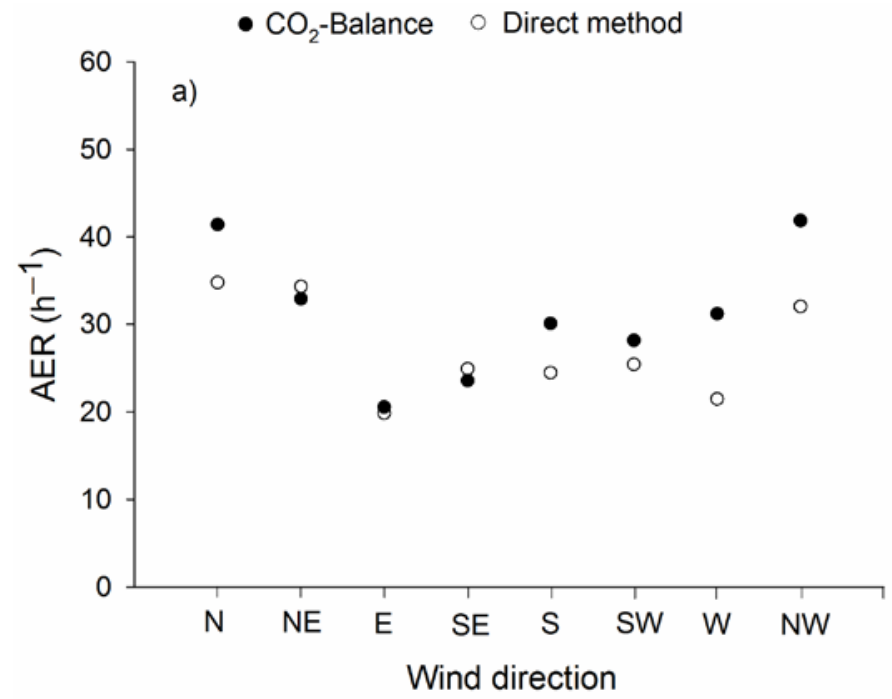

621

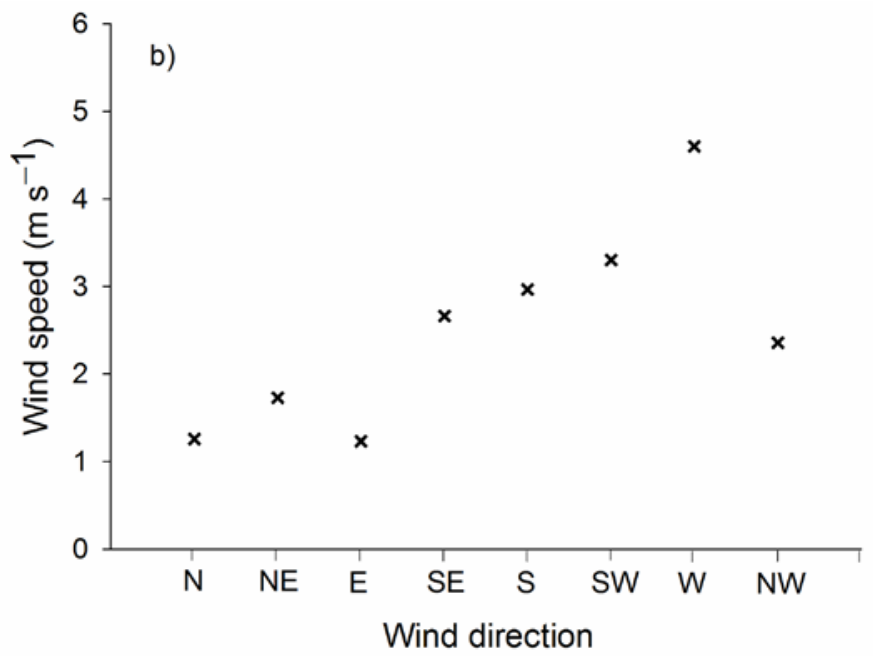


624 Fig. 11 Effect of a) $\mathrm{CO}_{2}$ concentration difference $\left(\Delta \mathrm{CCO}_{2}\right)$ and b) temperature difference $(\Delta \mathrm{T})$ on $\mathrm{CO}_{2}$ 625 balance method (The data points with values beside them were derived from original data prior to 626 application of the 1.5IQR rule to detect outliers).

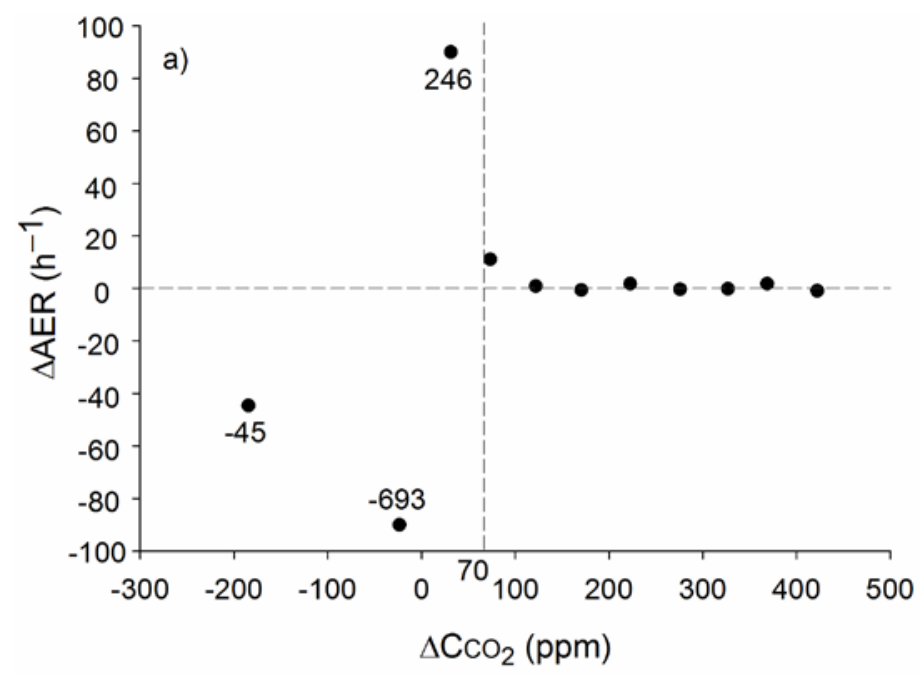

627

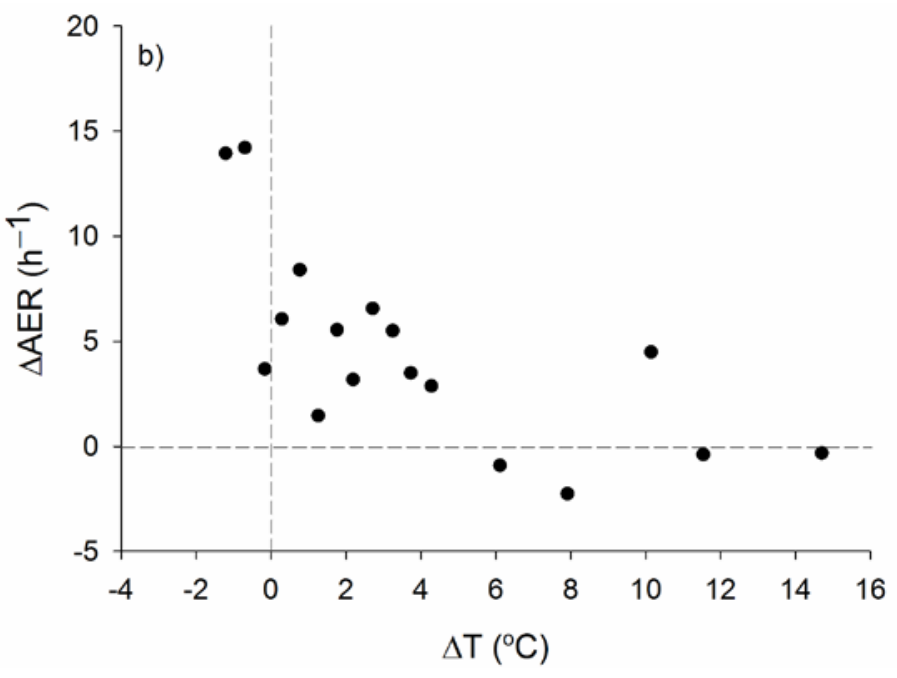


630 Fig. 12 Diurnal AER by direct method (-) and $\mathrm{CO}_{2}$-balance method (- - -). The hatched areas mark the 631 time periods when milking, the periods marked by arrows indicate the steady state phases.

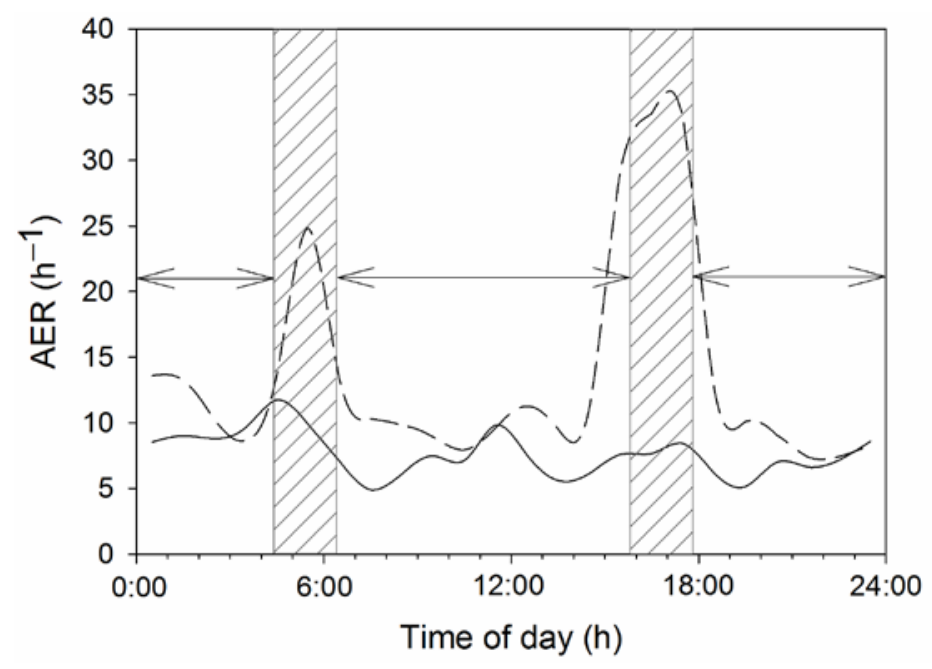

632

633 
634 Table 1 Data collection periods and environmental conditions.

\begin{tabular}{cccccc}
\hline \multirow{2}{*}{ Seasons } & \multirow{2}{*}{ Month } & \multirow{2}{*}{$\begin{array}{c}\text { Wind speed } \\
\left(\mathrm{m} \mathrm{s}^{-1}\right)\end{array}$} & \multicolumn{2}{c}{ Temperature $\left({ }^{\circ} \mathrm{C}\right)$} & Curtains \\
\cline { 4 - 5 } & & $3.3 \pm 3.3$ & $9.9 \pm 4.0$ & $6.7 \pm 3.7$ & Fully closed \\
Winter & March & $3.8 \pm 3.6$ & $15.5 \pm 3.3$ & $14.2 \pm 3.8$ & Fully open \\
Spring & May & $3.8 \pm 0$ & Outdoors & condition \\
Summer & July & $2.3 \pm 1.9$ & $27.6 \pm 6.1$ & $27.1 \pm 6.6$ & Fully open \\
Autumn & September & $1.5 \pm 1.4$ & $23.7 \pm 8.2$ & $20.9 \pm 6.1$ & Fully open \\
\hline
\end{tabular}

635

636 
637 Table 2. Analysis of variance between hourly means of AER based on the $\mathrm{CO}_{2}$-balance

638 method and AER difference ( $\triangle \mathrm{AER}$ ) between $\mathrm{CO}_{2}$-balance method and direct method

639 determined with respect to eight wind directions and two wind speeds regimes (high and low).

\begin{tabular}{|c|c|c|c|c|c|}
\hline $\begin{array}{l}\text { Wind } \\
\text { direction }\end{array}$ & $\begin{array}{l}\text { Wind direction } \\
\text { range }\left(^{\circ}\right)\end{array}$ & $\mathrm{n}$ & $\begin{array}{c}\text { Mean wind speed } \\
\left(\mathrm{m} \mathrm{s}^{-1}\right)\end{array}$ & $\begin{array}{c}\mathrm{AERCO}_{2} \\
\left(\mathrm{~h}^{-1}\right)\end{array}$ & $\begin{array}{c}\triangle \mathrm{AER} \\
\left(\mathrm{h}^{-1}\right)\end{array}$ \\
\hline NW & $292.5-337.5$ & 70 & 2.36 & $41.9^{\mathrm{A}^{*}}$ & $9.9^{A}$ \\
\hline $\mathrm{N}$ & $337.5-22.5$ & 81 & 1.25 & $41.4^{\mathrm{AB}}$ & $7.0^{\mathrm{ABC}}$ \\
\hline $\mathrm{NE}$ & $22.5-67.5$ & 66 & 1.73 & $32.9^{\mathrm{BC}}$ & $-3.3^{\mathrm{D}}$ \\
\hline $\mathrm{W}$ & $247.5-292.5$ & 116 & 4.60 & $31.2^{\mathrm{CD}}$ & $9.9^{\mathrm{AB}}$ \\
\hline $\mathrm{S}$ & $157.5-202.5$ & 54 & 2.97 & $30.1^{\mathrm{CD}}$ & $5.6^{\mathrm{ABC}}$ \\
\hline SW & $202.5-247.5$ & 107 & 3.30 & $28.2^{\mathrm{CDE}}$ & $2.5^{\mathrm{BCD}}$ \\
\hline SE & $112.5-157.5$ & 54 & 2.66 & $23.6^{\mathrm{DE}}$ & $-3.1^{\mathrm{D}}$ \\
\hline $\mathrm{E}$ & $67.5-112.5$ & 44 & 1.23 & $20.5^{\mathrm{E}}$ & $0.6^{\mathrm{CD}}$ \\
\hline $\begin{array}{l}\text { Wind speed } \\
\text { regime }\end{array}$ & $\begin{array}{l}\text { Wind speed range } \\
\qquad\left(\mathrm{m} \mathrm{s}^{-1}\right)\end{array}$ & $\mathrm{n}$ & & $\begin{array}{c}\mathrm{AERCO}_{2} \\
\left(\mathrm{~h}^{-1}\right)\end{array}$ & $\begin{array}{c}\triangle \mathrm{AER} \\
\left(\mathrm{h}^{-1}\right)\end{array}$ \\
\hline High & $>3$ & 189 & & $39.5^{\mathrm{a}}$ & $3.0^{\mathrm{a}}$ \\
\hline Low & $\leq 3$ & 403 & & $28.4^{\mathrm{b}}$ & $5.5^{\mathrm{b}}$ \\
\hline
\end{tabular}

640 "Values with the same upper case letter, in the same column, indicate either non-significant differences

641 in AER or AER differences ( $\triangle \mathrm{AER}$ ) between the $\mathrm{CO}_{2}$-balance and indirect methods with respect to

642 wind direction, while values with the same lower case letters indicate non-significance in AER or

$643 \Delta$ AER with respect to wind speed regime $(\mathrm{n}=$ number of data points in each data set).

644 
645 Table 3 Proportion of acceptable AER during the 4 to $6 \mathrm{pm}$ milking time based on $28 \mathrm{~d}$ mean hourly data.

\begin{tabular}{cccc}
\hline Data points & \multicolumn{3}{c}{$\mathrm{AERCO}_{2}$} \\
\cline { 2 - 4 } (7 d for four seasons) & $<\mu-3 \sigma$ & Acceptable & $>\mu+3 \sigma$ \\
\hline 56 & 7 & 29 & 20 \\
$\%$ & 12 & 52 & 36 \\
\hline
\end{tabular}

646 